2. That the best interests of physical medicine in the future lie in a closer and more practical link with general medicine and surgery.

3 . That the establishment of a committee for investigating claims for apparatus would largely stop the flood oi quack appliances.

\section{A CASE OF HOOKWORM DISEASE} BY

\author{
W. M. FALLON, M.D., B.Sc., D.P.H. \\ LECTURER IN CLINICAL MEDICINE, UNIVERSITY COLLEGE, GALWAY
}

The following case of ankylostomiasis furnishes several interesting points.

\section{CASE ReCORD}

In September, 1929, a missionary, aged 40, visiting me with a patient, mentioned casually that he himself was suffering from malaria, and asked me what dose of quinine would I recommend for the attacks. I said 10 grains three times a day, to be reduced after three or four days to 10 grains at night, etc. A year later the missionary again presented himself, complaining that he was suffering from malaria and that quinine did not relieve him. He looked sallow and melancholy ; complained of irritability, headaches, inability to concentrate, mental torpor, insomnia, lack of energy, and a slight pain over splenic area. He also complained of slight shivers and a feeling of fever coming on irregularly. A few days previously he had played hurling to make himself perspire, and on the following day he felt very ill. He said his feet and face were then swollen, and he stayed in bed for two days before coming to see me.

\section{Examination}

On examination the swelling of feet and face was not evident; the abdomen was soft and pultaceous, and a little diffuse soreness on palpation was present. The spleen was not enlarged. The cardiac first sound was rather sharp. The sclerotics had a faint yellowish tinge. His temperature was normal. As he had a feeling of feverishness, headache, and shivers the previous evening, I asked for a blood examination, feeling that, in such circumstances, a negative report, combined with a normal spleen, would point to some condition other than malaria. Examination by Professor T. Walsh revealed absence of malarial parasites in fresh and stained films and the following figures: red blood corpuscles, 4,438,000; haemoglobin, 85 per cent. ; colour index, 0.95 ; leucocytes, 26,600; eosinophils, 75 per cent. ; lymphocytes, 15 per cent. ; polymorphs, 10 per cent.

A specimen of the stools examined later showed the presence of the ova of ankylostoma in large numbers. To avoid the possibility of error in reference to the eosinophil figure another blood examination was made the next day, and the figures were substantially confirmed.

\section{Previous History}

The patient's past history was as follows. He arrived in Nigeria in November, 1923, and enjoyed fair health until early in 1925, when he began to suffer from what he thought was slight malaria. His symptoms were: a feeling of heat, though he could not perspire, slight pains in the abdomen, lack of appetite, slight shivers occurring irregularly, irritability, and depression. He gradually got worse, and at the end of six months had lost $28 \mathrm{lb}$. in weight. He improved somewhat until at the end of 1926 he went to live at Aginebode, on the banks of the Niger. He now noticed that his abdomen was sore, food felt heavy and sour, and his faeces were blackish. A long walk would produce swelling of his feet, his appetite became very poor, and he became thin, suffered from insomnia, depression, headaches, inability to concentrate, buzzing in the head, and repeated syncopes. Occasional rest einabled hin to carry on. About June, 1927, he got what he felt was an attack of asthma, which lasted three weeks. There was no history of dermatitis or "ground itch." He left for home in May, 1928. When he arrived home he recovered his appetite slowly, but the feverish feeling still persisted, and with it depression and sleeplessness.

\section{Treatment and Progress}

Instead of supper, $1 \mathrm{oz}$. of mist. alb. was given. In the morning 15 grains of powdered thymol in capsules were given every hour for three doses, and two hours after the last dose $1 \mathrm{oz}$. of mist. alb. was administered. Three days later, October 4th, 1930, a blood count showed: red blood corpuscles, 4,640,000; haemoglobin, 90 per cent.; colour index, 0.97 ; leucocytes, 15,240; eosinophils, 55 per cent. ; lymphocytes, 16 per cent. ; polymorphs, 25 per cent. ; monocytes, 3 per cent. ; basophils, 1 per cent.

On October 7 th ankylostoma eggs were seen in small numbers in the stools. On October 8th the thymol treatment was repeated. On October 9 th $0.5 \mathrm{c} . \mathrm{cm}$. of oil of chenopodium was administered every hour for three doses, 1 oz. of mist. alb. being given two hours after the last dose. On November 6th the patient returned for re-examination. No ova were found in the stools, but the blood count was practically the same as that of October 4 th, giving a white cell count of 50 per cent. eosinophils. On February 4th, 1931, the patient's blood was normal, showing only 1 to 2 per cent. of eosinophils, and all symptoms had disappeared and have not returned up to the present date.

\section{Discussion}

This case presents evidence that the hookworm can live for at least twenty-eight months, as the patient left Africa in May, 1928, and the ova were recognized in September, 1930. The possibility of reinfection at home may be eliminated, although the disease is not unknown in these islands (Cornwell bunches, etc.).

It also illustrates a very marked degree of eosinophilia. This is supposed to connote a high degree of resistance, and certainly the patient's condition was good considering the abundance of eggs and abnormal blood picture. It tends to confirm the opinion that a specific poison is elaborated in this disease. Headaches, melancholy, and inability to concentrate suggest a specific poison attacking brain and liver (the chief seat of eosinophil formation). The presence of these symptoms in the ordinary case of hookworm disease may be attributed to the usual resultant secondary anaemia, but its absence in this case and the absence of any other gross physical signs suggest that these symptoms resulted from the action of a specific poison, more especially as these symptoms disappeared on treatment.

The significance of eosinophilia is not yet understood. It may be associated with endocrine disturbance. In rapidly fatal cases of hookworm disease the eosinophilia diminishes. In hydatid disease eosinophilia disappears if suppuration of the cyst occurs. Petersen and Saelhof found that eosinophilia occurred in irradiated dogs only if the liver had been included in the irradiated area. In hookworm disease the tissue at the sites of the bites of the worm in the intestines is packed with eosinophils. The absolute and relative diminution in polymorphonuclear leucocytes and the absolute increase in lymphocytes may be noted in the blood picture of this case.

The absence of anaemia is a striking feature when we remember that the disease is called tunnel workers' anaemia, tropical chlorosis, Egyptian chlorosis, and that Whipple has demonstrated a haemolytic poison in the parasite.

Although the parasites were killed and eggs absent from intestines, evidently the poison still remained for quite a long period in the system, as we see no great change in the blood count after a month.

The blood picture, the persistence of the infection, and the reaction to treatment are points of clinical interest in the case to which I feel attention may profitably be drawn. 